\title{
A novel guidewire-assisted silicone spigot placement for endobronchial occlusion in a complicated airway tract: application of medical thoracoscopy
}

\author{
Yojiro Yutaka, Masahide Isowa, Hiroshi Date \\ Department of Thoracic Surgery, Kyoto University Hospital, Sakyo-ku, Kyoto Japan \\ Correspondence to: Yojiro Yutaka, MD, PhD. Department of Thoracic Surgery, Kyoto University Hospital, 54 Shogoin, Kawahara-cho, Sakyo-ku, \\ Kyoto 606-8507, Japan. Email: yutaka7@kuhp.kyoto-u.ac.jp.
}

Submitted Aug 13, 2019. Accepted for publication Dec 03, 2019.

doi: $10.21037 /$ jtd.2019.12.49

View this article at: http://dx.doi.org/10.21037/jtd.2019.12.49

The Endobronchial Watanabe Spigot (EWS) is a bronchoscopic device with a silicon plug used to occlude a bronchial fistula. Under bronchoscopy, localization of bronchopleural fistula poses a clinical issue and EWS placement in bilateral upper lobes often requires a skillful technique. To facilitate its placement, we introduced a new guidewire technique using two scopes, a bronchoscope and a medical thoracoscope, for localization of the bronchopulmonary fistula using a water-seal test and occlusion of the responsible bronchus without fluoroscopy. We report a case of a patient with chronic empyema with a bronchopleural fistula of the right upper lobe who had undergone a temporary Clagett open-window thoracostomy that was successfully occluded with four spigots using this new method.

A 55-year-old woman with a right Clagett openwindow thoracostomy was transferred to our hospital for a thoracoplasty. Six months earlier she suffered from respiratory distress from a right lung abscess (Klebsiella pneumoniae). Despite immediate intravenous administration of antibiotics, the lung abscess ruptured into her chest cavity and she presented with acute empyema. Although tube drainage was initiated, because of the continuous air leakage by empyema with the bronchopleural fistula, a Clagett open-window thoracostomy was performed to control the intrathoracic inflammation. After the entire thoracic cavity became aseptic owing to daily sponge exchange, the patient was transferred to our hospital for a thoracoplasty. However, prior to the thoracoplasty, bronchial occlusion with an EWS was required to treat the remaining bronchopleural fistula (Figure 1).

After general anesthesia, we first confirmed the air leakage points in the upper lung field using a water-seal test under an airway pressure of $30 \mathrm{cmH}_{2} \mathrm{O}$ via a medical thoracoscope. Because three air leakages sites existed in S1b, S2a and S3a, we placed three EWS in B1b, B2a, B3a. However, because air leakage continued under the water-seal test, we occluded B1a, leading to the eradication of air leakage from the bronchopleural fistula. To facilitate insertion of the spigot into the right upper lobe, a guidewire (Jagwire $0.035 \mathrm{~m} \times 4.5 \mathrm{~m}$ : Boston Scientific, Marlborough, MA) was inserted into the suspected bronchus via a bronchoscope. After the guidewire was confirmed to be advanced into the patient's chest cavity through the thoracoscope, keeping the guidewire in place and removing the bronchoscope, the EWS was pierced with a guidewire along the long axis via an $18 \mathrm{G}$ needle and pushed forward into the responsible bronchus using the tip of a flexible bronchoscope along the wire-guided path (Figures 1B, Video 1). After insertion of the EWS so as not to descend out of the bronchus, the guidewire was gently withdrawn from the bronchoscope (Figure 1C). This guidewire-assisted technique with the use of two scopes allowed for accurate localization of the bronchopleural fistula and easy placement of the four endobronchial spigots in B1a, B1b, B2a, and B3a of the apical lobe in 10 minutes (Figure 1D). Ten months later, a thoracoplasty with omentopexy was successfully 

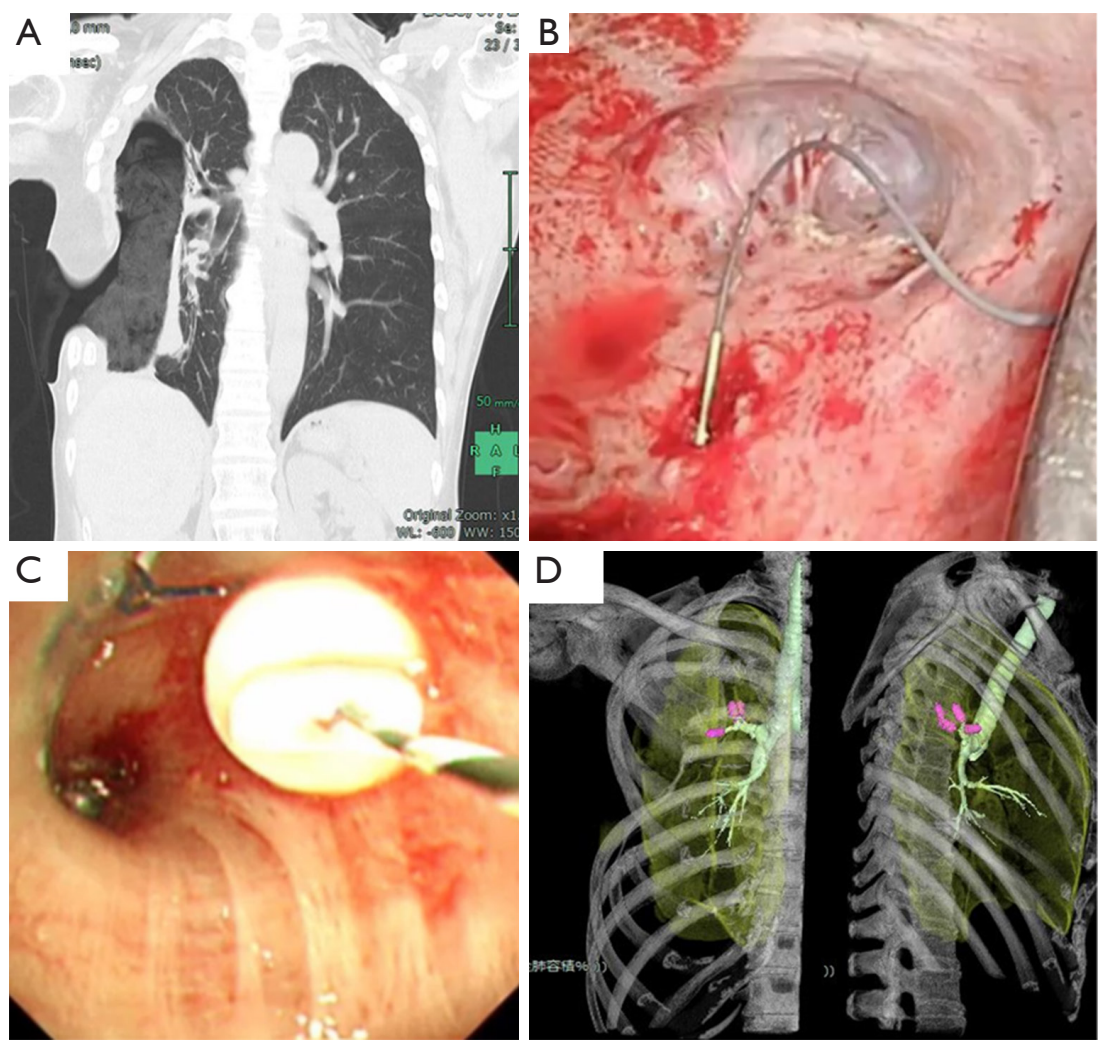

Figure 1 Guidewire-assisted Endobronchial Watanabe Spigot (EWS) placement. (A) Coronal CT findings of the right thoracic cavity with a Clagett-open window thoracostomy. (B) Intraoperative thoracoscopy showing the guidewire coming through the bronchopulmonary fistula from the airway tract. (C) Guidewire-assisted placement of the endobronchial spigot. (D) Positions of the EWS placement (four pink marks).

performed on the patient. The operation was started in the semi-supine position for easy harvest of the omentum. All lobes were severely adhered to the chest wall. After skin resection around the window rim, ventral adhesion between the middle lobe and chest wall was minimized towards the retrosternum space with careful attention not to injure the fragile lung. After the omentum was mobilized into the right thoracic space via the retrosternal space, it was securely stitched to the air leakage points confirmed at the prior EWS placement with 4-0 Prolene. An additional rib resection was not performed; two ribs $\left(5^{\text {th }}\right.$ and $6^{\text {th }}$ ribs $)$ had already been resected, and we tried to occupy dead space with the pedicled pectoralis major muscle flap as much as possible. A drainage tube was inserted subcutaneously without suction to prevent detachment of the stitched omentum, and the chest wall was firmly banded by a sternal fixation band. The postoperative course was uneventful and the drainage tube was withdrawn 10 days postoperative. No recurrence of the empyema was observed one year after the operation.

Since the first repot in 1991 of Dr. Watanabe's use of a silicone plug for endobronchial occlusion, the Endobronchial Watanabe spigot (EWS) (Harada Co. Osaka, Japan) has been widely used for the management of intractable pneumothorax and bronchopleural fistula (1). Although flexible bronchoscopy has improved and provided various endoscopic treatments, adequate airway visualization is often difficult during bronchoscopic procedures, particularly in spigot placements. Moreover accurate localization of bronchopleural fistula under bronchoscopy poses a clinical challenge. Medical thoracoscopy is a minimally invasive procedure that allows for direct visualization of the intrathoracic state and therapeutic interventions (2). In this case, the combined visualization 
with a bronchoscope and medical thoracoscope provided adequate visualization of the intrathoracic space and enabled the localization of the bronchopleural fistula. Using two scopes, the guide wire technique allowed for simple and easy EWS placement without intraoperative fluoroscopy compared to the grasping technique that requires both adequate bronchoscopic visualization and cooperative manipulation with assistance through a working channel (3).

The EWS placement technique using a guidewire was first reported by Miyazawa et al. in Japan, in which they successfully placed 123 spigots in 26 patients for intractable pneumothorax (4). Although they selected a balloon occlusion test for identification of responsible bronchi, it was common that occlusion of all bronchus in a whole lobar unit was necessary by collateral ventilation to eradicate the air leakage detected from the chest tube. Our case also required $\mathrm{B} 1 \mathrm{a}, \mathrm{B} 1 \mathrm{~b}, \mathrm{~B} 2 \mathrm{a}$, and $\mathrm{B} 3 \mathrm{a}$ occlusion for air leakage in the upper lobe. However, introduction of a medical thoracoscope could provide adequate intrathoracic working space to accurately identify the air leakage points, which enabled easy EWS placement. To prevent injury of fragile lung parenchyma, it may be better to introduce a medical thoracoscope with intraoperative fluoroscopy. In a series by Miyazawa, $10.6 \%$ EWS migration (13 of 123 spigots) was also reported (4). Regarding the EWS dropout, in our case, because one EWS migrated from $\mathrm{B} 2 \mathrm{a}$ to the abdomen one day after the procedure, as observed by X-ray, another EWS placement procedure was performed. Over the past few decades, alternative bronchoscopic occlusion devices using unidirectional endobronchial valves, Zephyer endobronchial valves (Zephyr, Pulmonx Corporation-Redwood City, CA, USA) and Spiration intra bronchial valves (Olympus Respiratory America-Redmond, WA, USA) have been approved for humanitarian use for the management of emphysema and persistent air leaks. A multicenter study in Italy reported valve migration in $2.1 \%$ of patients (9/423). Although a unidirectional endobronchial valve retains its implanted position compared to EWS, migration can occur 3.7 months after the implantation (5).

An open-window thoracotomy was first described by Dr. Oscar Clagett in 1963 for treating a postpneumonectomy empyema (6). This technique is still used in the management of bronchopleural fistula to reduce intrathoracic inflammation. While this method reduces the patient's quality of life because of daily gauze exchange, it can also act as a bridge to secondary wound closure with muscle or omental flaps once the infection of the pleural cavity is under control using bronchial occlusion. For successful chest closure following open-window thoracostomy, it is essential to close the suspected bronchopleural fistula.

Guidewire-assisted endobronchial spigot placement with two scopes, a bronchoscope and medical thoracoscope, is a feasible alternative to the grasping method. This combination technique may be simpler for cases of a Clagett open window where adequate working space may be secured by a medical thoracoscope.

\section{Acknowledgments}

We thank Ashleigh Cooper, from Edanz Group (https://enauthor-services.edanzgroup.com/) for editing a draft of this manuscript.

Funding: None.

\section{Footnote}

Conflict of Interest: The authors have no conflicts of interest to declare.

Ethical Statement: The authors are accountable for all aspects of the work in ensuring that questions related to the accuracy or integrity of any part of the work are appropriately investigated and resolved

Open Access Statement: This is an Open Access article distributed in accordance with the Creative Commons Attribution-NonCommercial-NoDerivs 4.0 International License (CC BY-NC-ND 4.0), which permits the noncommercial replication and distribution of the article with the strict proviso that no changes or edits are made and the original work is properly cited (including links to both the formal publication through the relevant DOI and the license). See: https://creativecommons.org/licenses/by-nc-nd/4.0/.

\section{References}

1. Watanabe Y, Matsuo K, Tamaoki A, et al. Bronchial occlusion with endobronchial Watanabe spigot. J Bronchol 2003;10:264-7.

2. Murthy V, Bessich JL. Medical thoracoscopy and its evolving role in the diagnosis and treatment of pleural disease. J Thorac Dis 2017;9:S1011-21.

3. Kida H, Muraoka H, Inoue T, et al. A Novel Technique for the Placement of Endobronchial Watanabe Spigots Into the Bronchus: Side-Grasping Method. J Bronchology Interv Pulmonol 2016;23:71-5. 
4. Miyazawa H, Shinno H, Noto H, Fujisaka S, et al. Bronchial Occlusion Using EWS (Endoscopic Watanabe Spigot) by Push \& Slide Method and a Pilot Study of Bronchoscopic Lung Volume Reduction Using EWS for Severe Emphysema. J Jpn Soc Respir Endosc 2003;25:695-703.

5. Fiorelli A, D'Andrilli A, Bezzi M, et al. Complications

Cite this article as: Yutaka Y, Isowa M, Date H. A novel guidewire-assisted silicone spigot placement for endobronchial occlusion in a complicated airway tract: application of medical thoracoscopy. J Thorac Dis 2020;12(3):1138-1141. doi: 10.21037/ jtd.2019.12.49 related to endoscopic lung volume reduction for emphysema with endobronchial valves: results of a multicenter study. J Thorac Dis 2018;10:S3315-25.

6. Clagett OT, Geraci JE. A procedure for the management of postpneumonectomy empyema. J Thorac Cardiovasc Surg 1963;45:141-5. 